\title{
SISTEM MULTIPLE CROPPING TANAMAN SAYURAN SEBAGAI ALTERNATIF PENINGKATKAN PENDAPATAN PETANI DI CURUP UTARA REJANG LEBONG
}

\section{MULTIPLE CROPPING VEGETABLE PLANT SYSTEM AS THE ALTERNATIVE OF ENHANCEMENT FARMER'S INCOME AT CURUP UTARA REJANG LEBONG}

\author{
Oleh: \\ Dwi Fitriani, Fiana Podesta, dan Ririn Harini \\ Program Studi Agroteknologi \\ Fakultas Pertanian Universitas Muhammadiyah Bengkulu \\ Email: tiza321@yahoo.com
}

\begin{abstract}
The events have been held in farmer Group Manggala Curup Village and farmer Group Melati Siguring Village, Sub-district North Curup, District Rejang Lebong. Most of farmers in Curup Village and Seguring Village, Sub-district North Curup, plant vegetable plants in monoculture and do not use a good quality of seed. Farmers have good potential to improve the result and the income with avoiding crop failures or the plummeted of market price. These things will be able to be covered by other plants that can be obtained with intensive use of land by using multiple copping to vegetable plants that have high economy and use of good quality of seeds. The purpose of doing training are (1) farmer group has knowledge about intensification of land using multiple cropping and good quality of seeds (2) farmers are able to be producer of seeds in order to decrease the cost incurred in the next growing season and increace the income. The methods that will be used in training are (1) counselling and education about the agriculture of multiple cropping, good quality of seed, and the way to get good quality of seeds (2) production of demonstration plot (demplot) trial to apply multiple cropping and good quality of seeds. (3) Mentoring system of farmer group. The result of the activity is being able to improve insight of farmer, in the terms of intensification land by using multiple cropping and good quality of seeds. Besides that, farmers can produce their own seeds to the next growing season. The income of farmers in multiple cropping systems of vegetable plants will be higher if it is compared with monoculture system.
\end{abstract}

Keywords: vegetable plant, multiple cropping, good quality of seed

\section{PENDAHULUAN}

Tanaman sayuran meinginkan lingkungan tinggi tempat, suhu, kelembaban dan curah hujan yang cukup untuk pertumbuhan ini seperti Kabupaten Curup Utara memiliki dengan ketinggian tempat $500-1.200 \mathrm{~m}$ dpl, suhu $23-32{ }^{\circ} \mathrm{C}$, kelembaban $40-80 \%$, curah hujan $2.376-4.533 \mathrm{~mm}$ pertahun dengan intensitas matahari $7-19$ jam per hari (BPP, 
2015). Kecamatan ini merupakan pemasuk sayuran untuk Propinsi Bengkulu bahkan di daerah lainnya seperti Lubuk Linggau dan Palembang.

Petani sayur di kecamatan Curup utara mengusahakan tanaman sayur seperti: cabe, buncis, wortel, sawi, timun dan tomat namun kebanyakan petani mengusahakan tanaman secara monokultur dan benih yang digunakan belum menggunakan benih yang bermutu dan bersertifikat. Menurut Yatim (2004), benih yang digunakan secara terus menerus dari generasi ke generasi akan mengalami penurunan mutu benih, hal ini menyebabkan produksi yang dihasilkan akan semakin menurun. Penggunaan benih bermutu dapat meningkatkan hasil $50 \%$ dan juga menggunakan pola tanam yang baik memiliki keuntungan mengefisienkan penggunaan sumber daya yang ada, mengintensifkan menggunaan lahan, meningkatkan produksi/frekuensi panen, mengurangi resiko kegagalan panen, meningkatkan penyebaran tenaga kerja sepanjang tahun, mencegah kerusakan tanah dan diversifikasi pangan /beraneka ragam gizi serta efisien penggunaan tenaga kerja keluarga meningkat (Djakfar et al., 1999).

Kebanyakan petani mempunyai lahan sendiri namun pengolahannya belum secara optimum/ intensif seperti penggunaan pupuk, bibit, permintaan pasar hal ini disebabkan keterbatasan ilmu yang dimiliki petani. Petani biasa menanam jenis tanaman yang biasa mereka tanam tanpa ingin mengusahakan tanaman yang lebih baik atau mengusahakan tanaman yang memiliki nilai ekonomi yang lebih tinggi di samping itu petani kita kebanyak latah artinya ikut-ikutan petani yang lain sehingga dapat menyebabkan hasil yang berlimpah dan harga akan menjatuh walaupun produksi tinggi namun pendapatan petani menjadi tetap rendah. Sebaiknya petani harus berani menanam jenis tanaman yang belum banyak diusahakan, atau dipasaran masih kurang, sehingga harga yang akan diperoleh petani lebih baik.

Tanaman hortikultura di daerah Curup Utara Kabupaten Rejang Lebong terlihat belum efisiennya dalam penggunaan lahan, pada tahun 2014 memiliki lahan pertanian untuk tanaman sayuran seluas 1.299 ha dengan produksi $13.804,8$ ton sedangkan pada tahun 2013 turun dengan produksi 348.191 ton (BPP, 2014). Disamping itu petani juga mengusahakan tanaman secara monokultur terlihat antara luas lahan tanam dan luas panen jauh berbeda seperti untuk tanaman kentang luas tanam 97 ha yang panen 69 ha $(28,87 \%)$, cabe luas tanam 379 ha yang panen 325 ha (14,24\%), bawang daun luas tanam 178 ha yang panen 153 ha $(14,04 \%)$, tomat luas tanam 87,5 ha luas panen 76,5 ha $(12,57 \%)$, wortel luas tanam 405 ha luas panen 356 ha (12,10\%), seledri luas tanam 21 ha dengan luas panen 19 ha $(9,52 \%)$, dan buncis luas tanam 79 ha dengan luas panen 54 ha $(31,64 \%)$ (BPP, 2014). Lokasi pengabdian pada Masyarakat ini ditujukan pada daerah yang memiliki potensi pengembangan sayuran, selain itu juga petani di daerah tersebut menanam jenis tanaman yang sama antar petani dengan tidak memperhatikan permintaan pasar, dan juga produksinya per hektar masih sangat rendah. Seperti Cabe7,89 ton/ha, bawang daun 1,74 ton/ha, tomat 5,53 ton/ha, wortel 11,36 ton/ha, Arcis 0,5 ton/ha dan buncis 1,35 ton/ha, 
timun 15,56 ton/ha. Bila dibandingkan dengan potensi hasil yang biasa yang dicapai, produksi ini masih rendah (BPP, 2014).

Dari tinjauan kelapangan dan laporan petani ternyata hanya sebagian kecil petani yang menggunakan benih bermutu dan selain itu hanya sekitar $10 \%$ petani telah mengintensifkan lahan pertaniannya dengan menerapkan pola tanam dan penggunaan benih Bermutu. Oleh karena itu jika petani diberi percontohan dengan sistem demplot dan penyuluhan terpadu tentang pola tanam/multiple cropping dan penggunaan benih bermutu dalam sistem budidaya diharapkan mampu melebihi kebutuhan keluarganya sehingga dapat menambah pendapatan petani sayur di Kecamatan Curup Utara. .

Menurut Mugnisyah dan Setiawan (1990), penyediaan benih harus memenuhi kriteria enam tepat yaitu: varietas, lokasi, waktu, jumlah, mutu dan tepat harga. Mengingat ke-6 kriteria tersebut tidak dapat dipenuhi oleh petani, akan tetapi perbenihan mereka dapatkan sendiri namun hasilnya hanya belum maksimal, karena benih yang digunakan dari pertanian budidaya konvensional.

Disamping itu lahan yang petani miliki masih banyak yang belum dimanfaatkan dan kelihatan petani hanya ingin menanam tanaman yang biasa mereka usahakan seperti pare, kisik/oyong, terong, kacang panjang, kacang buncis, kacang merah, kol, sawi cina, dan lain-lainnya yang bila dilihat dari segi ekonominya mempunyai nilai yang rendah, dan kebanyakan petanipun mengusahakan tanaman secara monokultur, sehingga pendapatan petani tidak jauh berbeda dari musim ke musim.

Oleh karena itu jika petani diberi percontohan dengan sistem demplot dan penyuluhan terpadu tentang pola tanam/multiple crop dan penggunaan benih bermutu dalam sistem budidaya diharapkan mampu melebihi kebutuhan keluarganya sehingga dapat menambah tingkat kesejahteraan petani sayur di Kecamatan Curup Utara.

Tujuan kegiatan pengabdian adalah untuk meningkatkan pengetahuan dan kesadaran petani akan pentingnya penggunaan benih bermutu dengan menggunakan sistem pertanaman multiple cropping. Selain itu kegiatan ini juga bertujuan untuk menjadikan petani sebagai peghasil benih bermutu sehingga dapat meningkatkan pendapatan petani

\section{METODE PENGABDIAN}

Kegiatan pengabdian dilaksanakan di Kelompok Tani Manggala Desa Curup dan Kelompok Tani Melati Desa Siguring Kecamatan Curup Utara Kabupaten Rejang Lebong, dari bulan Maret sampai Oktober 2016.

Pelaksanaan Pengabdian ini dilakukan dengan beberapa tahapan:

a. Sosialisalisasi kegiatan program

Agar kegiatan pengabdian yang sudah direncanakan bisa berjalan dengan baik maka dilakukan kegiatan sosialisasi program tentang budidaya tanaman sayuran secara multiple cropping dan penggunaan benih bermutu.

b. Pendidikan dan Penyuluhan 
Untuk menambah pengetahuan dan wawasan petani tentang penanamam sistem multiple cropping dan penggunaan benih bermutu maka dilakukan penyuluhan pertanian di kedua kelompok tani

\section{c. Demplot Percobaan}

Pembuatan demontrasi plot/demplot yaitu pembuatan beberapa petak tanaman yang berukuran $80 \mathrm{~cm}$ x $20 \mathrm{~m}$ sebanyak 4 petakan dengan menggunakan benih yang bermutu dan beberapa jenis tanaman yang memiliki nilai ekonomi yang tinggi.

\section{d. Pendampingan}

Setelah pembuatan demplot, diharapkan petani bisa menerapkan sistem pertanian multiple cropping pada tanaman sayuran. Kegiatan pemeliharaan tanaman dan pengamatan terhadap pertumbuhan tanaman dilakukan oleh anggota kelompok tani. Tim pengabdian tetap melakukan pendampingan dengan melakukan kunjungan ke lapangan. Sampai kegiatan panen dan pasca panen dari tanaman. Untuk meyakinkan petani dilakukan gambaran analisis usahatani yang akan membuktikan bahwa bertanam secara multiple cropping akan meningkatkan pendapatan.

\section{HASIL DAN PEMBAHASAN}

Berdasarkan koordinasi yang dilakukan dengan ketua kelompok tani, kegiatan penyuluhan dilakukan di kedua lokasi kelompok Tani. Benih yang digunakan disiapkan oleh anggota tim, yaitu benih cabe keriting, cabe rawit, buncis, tomat, sawi, mentimun Sedangkan bibit daun bawang disiapkan oleh kelompok tani, hal ini menunjukkan antusias petani untuk dapat mengikuti program yang akan dilakukan.

Penyuluhan dilakukan agar anggota kelompok tani lebih memahami tentang budidaya secara multiple cropping khususnya dilahan sempit karena akan mempertinggi daya guna tanah sehingga pendapatan petani akan meningkat akan mampu menghemat tenaga kerja. Selain itu dalam penyuluhan disampaikan juga tentang pentingnya menggunakan benih bermutu untuk pendapatkan hasil yang maksimum, sehingga ketika petani menerapkan pertanaman secara multiple cropping dan benih yang digunakan adalah benih bermutu maka akan meningkatkan pendapatan petani.

Untuk meyakinkan anggota kelompok tani dilakukan pembuatan demplot sistem pertanaman secara multiple cropping, sistem pertanian ganda yang sangat cocok bagi petani yang memiliki lahan sempit sehingga dapat memaksimalkan produksi dengan input luar yang rendah sekaligus meminimalkan resiko gagal panen jika dilakukan pertanaman secara monokultur.

Pada demplot dilakukan penanaman beberapa jenis tanaman yaitu cabe keriting, cabe rawit, buncis, tomat, sawi, timun, dan bawang daun. Penanaman tidak dilakukan secara bersamaan, tetapi seacara berurutan sehingga petani bisa memanfaatkan ruang dan waktu seefisien mungkin. 
Kegiatan yang dilakukan paling awal adalah dilakukan penyemaian benih cabe, cabe rawit, setelah bibit cabe dipindahkan ke lapangan dilakukan penyemaian benih tomat dan secara berurutan dilakukan penanaman sawi, buncis, timun dan daun bawang.

Pendapatan petani dengan sistem multiple cropping untuk luas tanam $100 \mathrm{~m}^{2}$ yang terdiri dari 4 petak tanam yang berukuran $0,8 \mathrm{~m}$ x $20 \mathrm{~m}$ sebesar $\mathrm{Rp} 1.983 .100,-$. Pendapatan sistem monokultur dengan luas tanam yang sama dengan sistem multiple cropping berdasarkan wawancara dengan kelompok tani lebih rendah. Pendapatan petani pada sistem multiple cropping lebih tinggi jika dibandingkan dengan sistem monokultur, karena pada sistem multiple cropping dapat menekan biaya, baik biaya tetap maupun biaya variabel, seperti biaya sewa lahan, biaya penyusutan peralatan, biaya benih, biaya pupuk, biaya tenaga kerja dan biaya obat-obatan. Selain itu dengan sistem multiple cropping juga dapat mengatasi harga yang turun pada satu poduk tertentu yang jumlah panennya melimpah pada sistem pertanian monokultur. Manfaat multiple cropping yaitu mengurangi erosi tanah atau kehilangan tanah-olah, memperbaiki tata air pada tanah-tanah pertanian, menyuburkan dan memperbaiki struktur tanah, mempertinggi daya guna tanah sehingga pendapatan petani akan meningkat pula, mampu menghemat tenaga kerja, menghindari terjadinya pengangguran musiman karena tanah bisa ditanami secara terus menerus. Pengolahan tanah tidak perlu dilakukan berulang kali, mengurangi populasi hama dan penyakit tanaman, dan memperkaya kandungan unsur hara antara lain nitrogen dan bahan.

Produksi tanaman sayur-sayuran yang ditanam tidak semuanya dipanen, tetapi disisakan sebanyak $5 \%$ dari populasi tanaman untuk dijadikan benih, sehingga petani bisa menjadi produsen benih. Tanaman yang disisakan untuk benih harus merupakan tanaman yang bebas dari hama dan penyakit.

Adapun analisis usahatani untuk sistem pertanaman multiple cropping yang dilakukan di demplot adalah sebagai berikut:

Benih bermutu menjadi syarat utama dalam memaksimalkan hasil produksi tanaman. Faktor yang mempengaruhi mutu suatu benih, antara lain sumber benih. Benih yang diambil dari pohon induk yang mempunyai penampakan dan genetik yang baik, diharapkan akan mempunyai kualitas benih yang baik pula. Tingkat kemasakan benih pada waktu pemanenan; untuk menghasilkan benih yang bermutu, pemanenan atau pengumpulan benih harus dilakukan setelah benih tersebut masak.

Mutu benih juga ditentukan oleh penanganan pasca panen, sebelum petani menyimpan benih, benih harus dikeringkan terlebih dahulu dengan cara pengeringan yang benar, benih dikeringkan sampai dengan kadar air tertentu (misalnya padi 13\%, kedelai $11 \%$ ), disimpan pada tempat yang sesuai, misalnya; suhu dan kelembabannya tidak terlalu tinggi serta bebas dari gangguan hama dan penyakit dan penanganan lainnya. Tahap selanjutnya untuk mendapatkan benih yang bermutu adalah dengan melakukan pembersihan dan pemilahan. 
Tabel 1. Analisis Usahatani Tanaman Sayuran dengan Sistem Multiple Cropping di Curup Utara Kabupaten Rejang Lebong

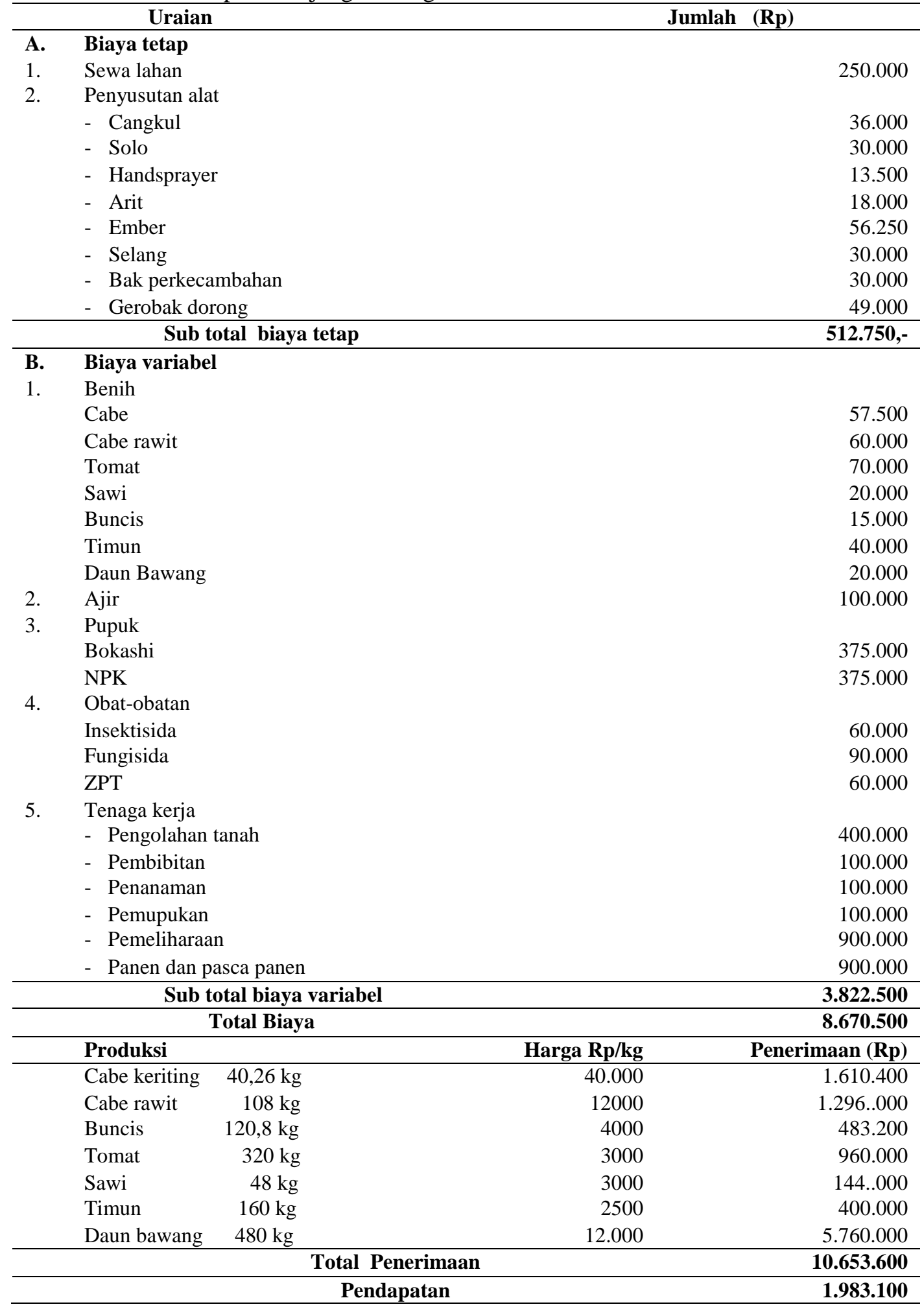


Petani mitra juga diajarkan bagaimana melakukan pengemasan yang baik terhadap benih, untuk menunggu benih sampai saatnya ditanam dan untuk mempertahankan mutunya selama disimpan, benih perlu dikemas dengan bahan kemasan (wadah) yang kedap udara seperti toples dan plastik.

Benih yang bermutu yang dihasilkan petani dalam sistem multiple cropping ini juga bisa menekan biaya untuk musim tanam berikutnya, sehingga diharapkan akan dapat meningkatkan pendapatan petani.

\section{KESIMPULAN DAN SARAN}

\section{Kesmpulan}

Dari hasil kegiatan pengabdian dapat disimpulkan bahwa:

1. Pelaksanaan kegiatan pertanaman secara multiple cropping mendapat respon positif dari kedua kelompok tani di Kecamatan Curup Utara, dan memberikan dampak positif karena dengan lahan yang terbatas yang dimiliki petani bisa meningkatkan pendapatannya.

2. Pelaksanaan program dapat menambah wawasan petani dalam mendapatkan benih yang bermutu, petani bisa menjadi penghasil benih, sehingga dalam musim tanam berikutnya dapat mengurangi biaya yang dikeluarkan.

\section{Saran}

1. Dalam pemilihan jenis tanaman dalam sistem pertanaman multiple cropping hendaknya dipilih tanaman komoditas tanaman sayuran yang memiliki nilai ekonomi yang tinggi.

2. Kelompok tani hendaknya dapat menjadi corong bagi petani yang lain di desanya, dalam menyebarkan informasi yang didapat dalam kegiatan program ini.

\section{DAFTAR PUSTAKA}

BPP, 2014, Laporan Tahunan BPP Kesambe Lama, Curup Timur Kabupaten Rejang Lebong.

Crowder, L.V., 2005, Plant Genetik, Terjemahan Kusdiarti Editor Soetarso, Fakultas Pertanian Universitas Gadjah Mada, Yogyakarta.

Direktorat Jendral Hortikultura, 2007, Pedoman Umum Pelaksanaan Pengembangan Agribisnis Hortikultura, Jakarta.

Djakfar Z.R., Dartius, Ardi, D., Suryati, E., Yuliadi, Hadiyono, Y., Syofyan, M., Aswad, S. Sagiman, 1999, Dasar-dasar Agronomi, Western University Agricultural Education Project, BKS-Bagian Barat.

Lakitan, B., 2000, Dasar-dasar Fisiologi Tumbuhan, Raja Grafindo, Jakarta. 
Meine van Noordwijk, Kurniatun Hairiah, 2006, Intensifikasi Pertanian Biodeversitas

Tanah dan Fungsi Agro Ekosistem, Agrivita, Vol 28 No.3. Oktober 2006.

Mugnisyah, W.Q., Asep Setiawan, 1990, Pengantar Produksi Benih, Rajawali, Jakarta.

Rukmana, 1994, Budidaya Tanaman Sayuran, Kanisius, Jakarta.

Sutopo L., 2001, Teknologi Benih, Gramedia, Jakarta.

Syukur, Muhammad, 2016, 8 Kiat Sukses Panen Sepanjang Musim Cabai, Agromedia Pustaka, Jakarta.

Yatim W., 2000, Dasar-dasar Ilmu Genetika, Gramedia, Jakarta.

Zulkarnain, 2010, Dasar-Dasar Hortikultura, Bumi Aksara, Jakarta. 